\title{
OMALIZUMAB DOSE STEP-UP AND TREATMENT RESPONSE IN PATIENTS WITH CHRONIC IDIOPATHIC/SPONTANEOUS URTICARIA (CIU/CSU): RESULTS FROM THE OPTIMA STUDY
}

Wayne Gulliver, ${ }^{1}$ Gordon Sussman, ${ }^{2}$ Jacques Hébert, ${ }_{1}^{3}$ Charles W. Lynde, ${ }^{4}$ Kim A. Papp, ${ }^{5}$ William H. Yang, ${ }^{6}$ Olivier Chambenoit, ${ }^{7}$ Antonio Vieira, ${ }^{8}$ Frederica DeTakacsy, ${ }^{8}$ Lenka Rihakova ${ }^{8}$

Faculty of Medicine, Memorial University of Newfoundland, St. John's, NL, Canada; '2Department of Medicine, University of Toronto, Toronto, ON, Canada;

sottawa Allergy Research Corporation, University of Ottawa Medical School, ON, Canada; 'Novartis Pharmaceuticals Corporation, East Hanover, NJ, USA; 'Novorartis Pharmaceuticals Canada Ince, Dorval, ac, Canad

\section{INTRODUCTION}

- The OPTIMA (efficacy of optimized retreatment and step-up therapy with [CTU/CSU]; NCTO2161562) study was designed to address some of the Omalizumab is approved for the treatment of adults and adolescents
(12 years and above) with CIUT/CSU who remain symptomatic despite

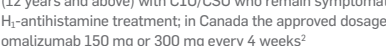
The treatment algorithm proposed by international guidelines states tha
the disease should be treated to complete resolution of symptoms - To date, no data evaluating the efficacy of step-up therapy

\section{OBJECTIVES}

- Forr objectives were to be answered in OPTIMA:

- If patient's signs and symptoms of CIU/CSU are well controlled
with omalizumab and the treatment is stopped, will the patient - If omalizumab treatment is restarted, will the patient respont
to retreatment?
- II the - If the patient does not sufficieintly respond to omalizumab $150 \mathrm{mg}$.
with step-tup the

-If the patient does not ressond to $300 \mathrm{mg}$, will treatment extension
itmorove the signs and symotoms of CrU/CSU? This poster will cover the third question

METHODS

study desig

- OPTIMA is a Phase 3b, international, multicenter, randomized,

open-label, noncomparator study

- Patients

$300 \mathrm{mg}$ for 24 weeks (1st dosing period)

- Based on weekly Urticaria Activity Score (UAST), patients entered one of

treatment for 12 more weeks (if $300 \mathrm{mg}$ initially and UAS7 >6 at Week 24 ) Patients who relapsed (UAST $\geq 16$ ) during the treatment withdrawal period

were retreated with the same dose (omalzzumab $150 \mathrm{mg}$ or $300 \mathrm{mg}$ every

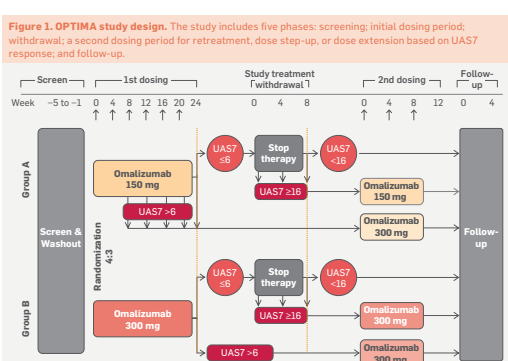

itgure 2. Patient randomization

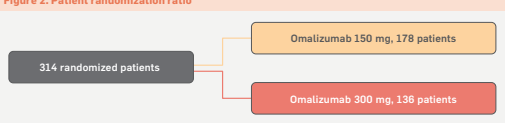

clusion criteria

Men or women at least 18 years of age

- Diagnosis of CIU/CSU and the presence of symptoms for $\geq 6$ months prior

- Patient must have been

the randomization visit

- UAS7 score $\geq 16$ (scale 0-42) and itch component of UAS7 $\geq 8$ (scale 0-21) Exclusion criteria

- Patients having a clearly defined underlying etiology for chronic urticaria Patients with urticaraial vasculitis, urticicaria pigmentosa, erythema

multifirmerm, mastocytosis, hereditary or accquired angioedema lymphom Or eukemia, active atopic dermatitis, bullous pemphiggid, dermatitis
herpetifiormis, senile pruritus or other skin disease associated with itch the study outcomes

Patients should stay on salignancy of any organ system

Hr-antihistaminie during entire trial duration. No resscue medication

\section{RESULTS}

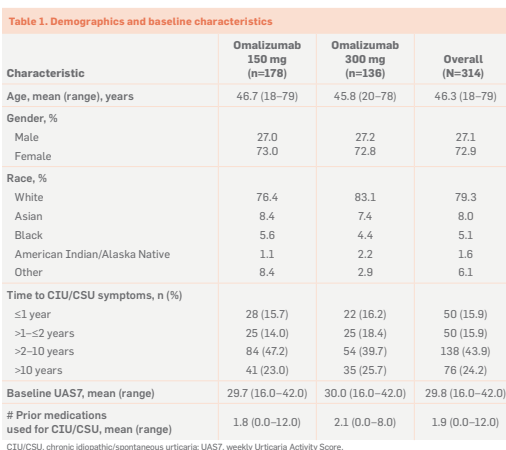

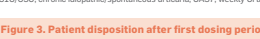

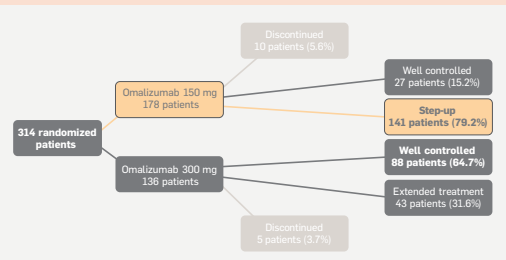

Of those patients with CIU/CSU treated with omalizumab $150 \mathrm{mg}$ REFERENCES

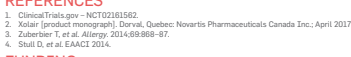

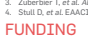

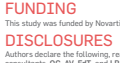
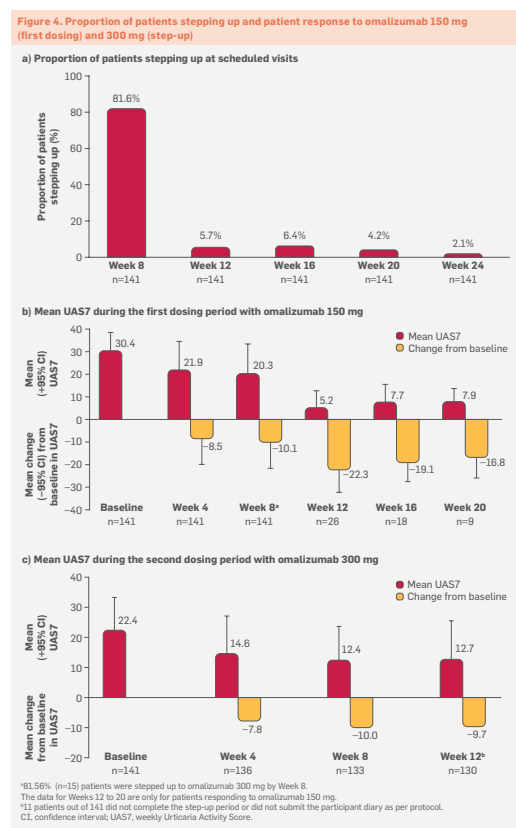

Step-up treatment to omalizumab $300 \mathrm{mg}$ led to a mean improvement
9.7 points in UAS7 when compared with the $150 \mathrm{mg}$ dosing period

ACKNOWLEDGMENTS

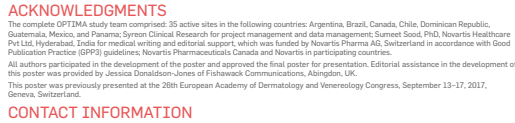

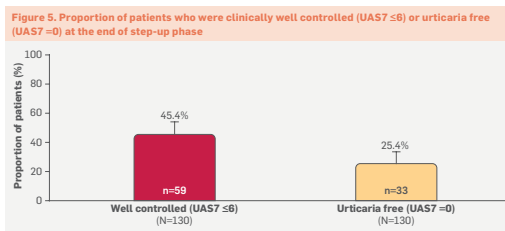
- Of those patients who had not been well controlled by omalizumab
$150 \mathrm{mg}, 45.4 \%$ were well controlled bey omalizuman $3000 \mathrm{~m}$ g during the
step-up phase, and $25.4 \%$ of these were even symptom free

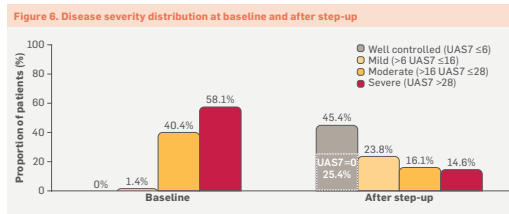

Step-up treatment improved the disease severity scenario

CONCLUSIONS

- Of the patients with cru/csu treated with omalizumab $150 \mathrm{mg}, 79.2 \%$
had to be up-dosed to $300 \mathrm{mg}$ owing to insufficient symptom control - The mean UAS7 improvement after the first dosing period and step-uI
therany was 8.0 points and 97 points, respestincly The - From the step-up patient group, $45.4 \%$ of patients achieved sympton
control during the 3 -month treatment with omalizumab $300 \mathrm{mg}$ - Disease severity distribution was improved after dose step-up,
with hhe majority of patients having well-controlled (45.4\%) or

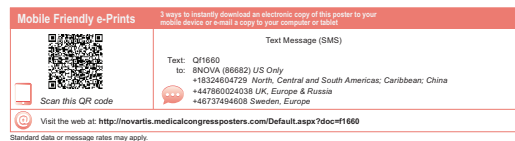

